DOI 10.35953/raca.v1i1.31

\title{
Os de comer dos baianos nas descrições dos cronistas e viajantes do século XIX
}

La comensalidad de los bahianos en las descripciones de cronistas y viajeros del siglo XIX

The commensality of bahians in the descriptions of 19th century chroniclers and travelers

\section{Vilson Caetano de Sousa Júnior ${ }^{1}$, Rafael Arcanjo Tavares Filho², Tayran Felipe Silva Vasconcelos ${ }^{3}$}

1 Doutor em Ciências Sociais, Pesquisador do Núcleo de Estudos em Alimentação e Cultura da Universidade Federal da Bahia. E-mail: vilsonjr@uol.com.br.

2 Nutricionista, Pesquisador do Programa Institucional de Bolsas de Iniciação Científica. E-mail: tavaresfilhor@gmail.com.

3 Gastronomo, Mestrando em Estudos Étnicos e Africanos. E-mail: vasconcelostayran@gmail.com.

\section{RESUMO}

O presente trabalho apresenta um panorama dos de comer na Bahia pelos olhares de viajantes no decurso do século XIX. Objetivo: Realizar um levantamento de descrições e observações de viajantes sobre a alimentação cotidiana dos baianos nos 1800. Metodologia: Foi realizada uma revisão bibliográfica com análise de conteúdo apoiada nos diários de viagem de quatro viajantes - Thomas Lindley, Johann Rugendas, Durval de Aguiar e Maximiliano de Habsburgo. Resultados: A categorização de dados identificou a importância da cultura da cana-de-açúcar e da mandioca, e seus derivados, para as refeições, mostrando-se essenciais para construção dos aspectos socioculturais da alimentação desse povo. Em paralelo, o consumo de vegetais e animais comestíveis presentes na cozinha, mostra a influência dos hábitos indígenas no consumo de vegetais silvestres e caças e da cultura africana no preparo de quitutes e pratos, até hoje conhecidos. Além disso, foram encontrados relatos sobre os hábitos alimentares e as maneiras de pôr a mesa, mostrados em concomitância aos alimentos e refeições, que em conjunto, sugerem uma representação dos de comer nos oitocentos. Conclusão: Essa pesquisa, favorece as discussões sobre as construções culturais dos hábitos alimentares contemporâneos, demonstrando que a comida é aquilo que é aceito socialmente e culturalmente por determinado grupo, e assim, indica novos debates sobre os de comer dos baianos.

Palavras-Chave: Alimentação; Visitantes; Bahia; Século XIX. 


\section{RESUMEN}

El presente artículo presenta una visión general de la comensalidad en Bahía (Brasil) a través de los ojos de los viajeros en el transcurso del siglo XIX. Objetivo: Realizar una revisión de descripciones y observaciones de viajeros sobre la comida diaria de los habitantes de Bahia en siglo XIX. Metodología: Se realizó una revisión bibliográfica con análisis de contenido basado en los diarios de viaje de cuatro viajeros: Thomas Lindley, Johann Rugendas, Durval de Aguiar y Maximiliano de Habsburgo. Resultados: La categorización de datos identificó la importancia del cultivo de la caña de azúcar y la yuca, y sus derivados, para la comensalidad, demostrando ser esenciales para la construcción de los aspectos socioculturales de la alimentacion de estas personas. Paralelamente, el consumo de vegetales y animales comestibles presentes en la cocina, muestran la influencia de los hábitos indígenas en el consumo de vegetales y de cazas silvestres y de la cultura africana en la preparación de manjares y platos, que todavía aún se conocen hoy. Además, se encontraron informes sobre hábitos alimenticios y formas de poner la mesa, mostrados en conjunto con alimentos y comidas, que juntos sugieren una representación de lo que comían en los años ochocientos. Conclusión: Esta investigación favorece las discusiones sobre las construcciones culturales de los hábitos alimentarios contemporáneos, lo que demuestra que la comida es lo que es aceptado social y culturalmente por un determinado grupo y, por lo tanto, indica nuevos debates sobre los hábitos alimenticios de los bahianos.

Palabras clave: Comida; Viajeros; Bahia; Siglo XIX.

\section{ABSTRACT}

This article presents an overview of comensality in Bahia (Brazil) through the eyes of travelers throughout 19th century. Objective: To carry out a survey of descriptions and observations of travelers about the eating habits of people from Bahia in the 1800s. Methodology: A bibliographic review was carried out with content analysis based on the travel diaries of four travelers - Thomas Lindley, Johann Rugendas, Durval de Aguiar and Maximilian Habsburg. Results: The categorization of data identified the importance of the culture of sugar cane and cassava, and their derivatives, for meals, proving to be essential for the construction of the socio-cultural aspects of the food of these people. In this line, the consumption of edible vegetables and animals present in the kitchen, shows the influence of indigenous habits on the consumption of wild vegetables and hunting animals and of African culture in the preparation of delicacies and dishes, which are still known today. In addition, reports were found on eating habits and ways of setting the table, shown in conjunction with food and meals, which together suggest a representation of those eating in the 1800s. Conclusion: This research favors discussions on the cultural constructions of contemporary eating habits, demonstrating that food is what is socially and culturally accepted by a certain group, and thus, indicates new debates on the eating habits of people from Bahia.

Keywords: Food; Visitors; Bahia; XIX century. 


\section{Introdução}

Este artigo reúne noções sobre a alimentação na sociedade baiana oitocentista através da análise dos diários de viagens de visitantes que passaram pela Bahia no decurso do século XIX. Buscamos fazer um levantamento destas descrições e observações sobre os chamados "de comer" dos baianos, expressão emprestada de Hildegarde Vianna que, com o delicado olhar de uma exímia folclorista, registrou em "A Cozinha Baiana: seu folclore e suas receitas" as minúcias riquezas de uma cozinha que se formava desde a atenção dada à plantação e ao cuidado dos animais, a preparações, ingredientes, maneiras de pôr a mesa e fazer as refeições: o que se come, como se come e os ritos envolvidos nesse ato. Assim, tratamos de analisar os "de comer" a partir da perspectiva dada pelos viajantes que se ocuparam de relatar suas impressões. Mesmo considerando que as informações destes visitantes sobre o "cardápio diário" das diferentes populações passavam pelas suas representações e imaginário pessoais, tais relatos não deixam de nos fornecer dados valiosos sobre a comensalidade, a maioria das vezes rechaçada dada a distância do paladar europeu e as 'maneiras de preparar' já arraigadas há mais de um século, onde várias cozinhas já dialogavam entre si como a portuguesa, a africana e a ameríndia.

Este trabalho começa demonstrando a importância dos relatos escritos e identificando os viajantes e suas obras escolhidas. Partindo para o corpus da pesquisa, trazemos os resultados da leitura interpretativa referente aos dados categorizados. Nos primeiros subitens mostramos como a mandioca, especialmente nas obras do início do século, e a cana-de-açúcar, no final do século, são importantes alimentos que estão acima da qualidade de comida: são fontes de renda, câmbios financeiros, compõem as tradições sagradas, ritualísticas e festivas, e assim interagem com toda sociedade.

Posteriormente discorremos os resultados encontrados nas categorias de "Frutas, verduras e outras espécies" e "Das carnes, peixes e mariscos", apontando os principais produtos de origem vegetal e animal que eram (ou ainda são?) consumidos, segundo os viajantes, mostrando em concomitante como estes produtos traduzem a visão do estrangeiro em terras brasileiras: "a terra que onde tudo que se planta, dá". Por fim, descrevemos os "Hábitos alimentares e a 
DOI 10.35953/raca.v1i1.31

comensalidade", que, sob a ótica dos visitantes, variavam entre classes sociais, econômicas, raças e pelas vilas e cidades da Bahia oitocentista.

\section{Metodologia}

Contamos para compor o corpus da pesquisa com as obras "Província da Bahia" de Durval Vieira de Aguiar (1), que data em 1880; da revisão "Visitante estrangeiros na Bahia oitocentista", de Moema Parente Augel (2); o livro "Bahia 1860: esboços de viagem" de Maximiliano de Habsburgo (3); "Narrativas de uma viagem ao Brasil" de Thomas Lindley (4), do período de 1802-3; assim como o diário de Johann Rugendas "Viagens pitorescas através do Brasil" (5), datada de 1820.

$\mathrm{Na}$ primeira fase da pesquisa fizemos uma leitura exploratória de cada obra supracitada, onde foi realizada uma investigação dos registros sobre a alimentação e comensalidade baiana no século XIX, combinando, para tanto, os métodos das pesquisas bibliográfica e documental. Foi realizada também uma leitura seletiva aos livros escolhidos com a finalidade de reunir os materiais de maior relevância e definir o corpus desse trabalho. Com os dados selecionados, esses foram classificados em cinco categorias, a saber: cana-de-açúcar (e derivados); mandioca (e derivados); vegetais comestíveis; carnes e animais comestíveis; e hábitos alimentares e comensalidade. Posterior a essa categorização, os dados foram interpretados para a redação deste artigo. Optamos pela separação do texto por subitens para apresentar os dados categorizados, para uma melhor leitura e visualização destas informações.

\section{Resultados e discussões}

\section{Os viajantes na Bahia dos 1800}

A primeira parte desse estudo compreendeu uma pesquisa bibliográfica através da leitura de fontes primárias produzidas a partir dos relatos de viajantes que passaram pelo Brasil em 1800. Esses autores e suas obras são importantes bases documentais para a historiografia do Brasil Colônia, e em especial da Bahia oitocentista. 
O Brasil era considerado uma colônia de grandes riquezas devido à sua mistura de símbolos, pelos seus inúmeros mistérios e culturas: dos segredos das matas amazônicas e seus mitos; dos índios e seus rituais; da mistura de cores e valores pela miscigenação com os negros escravizados de diversas regiões da África, mas principalmente pela fama dos solos férteis. Por conta disso, muitos estrangeiros, naturalistas, botânicos, pintores, médicos etc., desejavam visitar o Brasil como formas de ampliar seus conhecimentos. A Bahia, que até meados do século XVIII era capital da colônia, tinha localização privilegiada para que navios de estrangeiros abarcassem nessas terras (2). Dessa forma, muitos viajantes que gostariam de abarcar em terras brasileiras, passavam pelos portos baianos, a exemplo dos autores dos diários de viagem que estão presentes nessa pesquisa.

Thomas Lindley foi um comerciante inglês preso na Bahia acusado de contrabando de pau-brasil. No período em que esteve preso em terras brasileiras (1802-3), escreveu um diário (4) no qual relata suas impressões sobre a Bahia e cidades próximas que visitou em passagem, hábitos e costumes dos povos ali presentes misturados às suas frustrações e mágoas de estar preso em terras "tão inferiores quanto a sua" (pensamento frequente que é exprimido em todo seu diário). Sobre o que descreve, deixa claro em diversos momentos a intenção de "afugentar pensamentos e sofrimentos" impostos no período em que esteve preso, reverberando, dessa forma, na reparação de danos psicológicos e emocionais que sofreu durante seu cárcere. Entre relatos sobre a precariedade das prisões nos fortes em que esteve cativo e das injúrias sofridas neste período, Lindley descreve os hábitos e costumes alimentares da população, entre os percebidos nas cadeias e, nos períodos em que esteve em liberdade condicionada, nas vilas, fazendas, casas e demais imóveis nas cidades do São Salvador (chamada também de Bahia) e Porto Seguro, diferenciando-os socialmente.

Outro viajante que faz parte das referências para este artigo é Johann Rugendas, que visitou o Brasil no início do século XIX, registrando em "Viagens Pitorescas através do Brasil' (5), uma importante documentação sobre o Brasil oitocentista, onde relata - principalmente através de gravuras (que, em nossa interpretação, apresentam as mais interessantes e impressionantes referencias dessa obra) - os tipos, usos e costumes dos povos e paisagens do Brasil em 
meados de 1820. Na primeira parte do livro, o autor faz a interlocução entre as paisagens e estórias relevantes das províncias nas quais passou (Rio de Janeiro, Bahia e Pernambuco, além de alguns interiores do Brasil como Santos), destacando as monoculturas e plantações, discorrendo sobre os produtos mais encontrados nas províncias. Rugendas dedica apenas 5 páginas na primeira parte do seu trabalho para falar sobre a Bahia.

A terceira obra que está presente nesta pesquisa é "Província da Bahia" (1) datada da década de 80 do século XIX. Nela, Durval Vieira de Aguiar, incumbido pelo governo provincial, realizou uma viagem pela Província da Bahia para relatar a importância das vilas, municípios e interiores, como uma forma de "mercar" as terras baianas, suas riquezas e costumes ao europeu, que, numa espécie de "nova colonização", viria ocupar o espaço deixado pelo evento [e causas] da abolição da escravatura, no início de oitocentos. É nessa proposta que o autor viaja pelos interiores da Província e relata sobre os costumes e hábitos, riquezas das terras e mostra sobre a alimentação e lavouras mais presentes naquela década, dando a este artigo, um aspecto interessante, por detalhar essas informações em cada vila/ município/ terra da Bahia oitocentista, mesmo que demonstrando sempre determinada expectativa de fazer com que o leitor (o "novo colonizador") se encante por aquelas terras.

Maximiliano de Habsburgo, ou Maximiliano da Áustria, cujo nome verdadeiro era Fernando Maximiliano José de Habsburgo, era arquiduque da Áustria e Imperador do México. Primo de D. Pedro I, visitou à Bahia em 1860 e escreveu em "Bahia 1860: esboços de uma viagem" (3), seus achados sobre a Bahia oitocentista, em especial, a cidade de Salvador, na qual ficou por mais tempo hospedado. Apesar de sua visão preconceituosa sobre a população e da mentalidade típica à época em seus relatos sobre os povos brasileiros, apresenta em seu diário um riquíssimo arcabouço sobre a flora e botânica da Bahia do século XIX. Por esse motivo, apesar de não se ater às questões referentes a alimentação, a não ser nos momentos em que cita algumas frustradas experiências gastronômicas, ele nos propicia uma grande interpretação sobre os vegetais mais comumente consumidos à época.

Os viajantes consultados, mesmo imersos em propósitos e olhares limitados e cheios de preconceitos através de suas visões são importantes fontes de descrições 
DOI 10.35953/raca.v1i1.31

que aproximam o leitor aos costumes e hábitos dos oitocentos, ajudando, assim, a erigir uma historiografia alimentar, importante para se reforçar a discussão de que a comida está atrelada ao seu tempo e é uma construção social e cultural.

\section{Os de comer dos baianos ${ }^{1}$}

\section{A Cultura da Mandioca}

Ainda no século XVIII, era a mandioca e seus derivados, um dos gêneros que mais se destacava. Desta maneira a sua menção, em especial sobre a forma de farinha, aparece em Pernambuco e Rio de Janeiro, associada, sobretudo, às populações indígenas. Apenas Rugendas ${ }^{5}$ não cita esse produto ao falar sobre sua passagem pela Bahia.

Lindley ${ }^{(4)}$ e Aguiar (1) relatam a importância da farinha para a alimentação, lavoura e economia da Bahia no século XIX, mostrando como esse item se fez presente nos hábitos alimentares, estando a mandioca nas mesas de todas as classes sociais, e servindo como produto de exportação, em especial para outras províncias do Brasil, mas também para Portugal (Lindley, 1969, p. 156).

Em diversos momentos, Lindley relata a presença da lavoura da mandioca, mostrando sua imponência nas paisagens locais. Segundo as observações de Aguiar ${ }^{1}$, a plantação da mandioca é periódica, feita anualmente (p. 23), e, ao passar pelo município de Santo Antônio da Barra, surpreendeu-se: "a mandioca ali se produz admiravelmente em tamanho e qualidade; havendo raízes até com mais de metro de comprimento, pois que a terra a conserva inalterável por mais de dez anos" (Aguiar, 1979, p.189).

O principal produto da mandioca, na Bahia oitocentista, é a farinha, uma riqueza inestimável para os baianos, segundo os relatos obtidos nos diários de viagem de Lindley(4) e Aguiar (1). Para os visitantes, a produção e o hábito do consumo da farinha pelos portugueses se deu, em especial, porque o trigo ainda não havia se adaptado às lavouras da região, obrigando aos portugueses habituar-

\footnotetext{
${ }^{1}$ A expressão "de comer" como relatado na introdução é emprestado de Hildegarde Vianna ${ }^{(6)}$ e está relacionada não apenas ao que se come, mas como se come e às maneiras de se pôr a mesa.
} 
DOI 10.35953/raca.v1i1.31

se à farinha da mandioca, utilizada pelos índios da América do Sul (Lindley, 1969, p. 53). Com o bom clima para cultivo, a mandioca se espalhou por toda Província com destaque para as cidades de Nazaré, Santo Amaro, Valença e Santo Antônio da Barra, que, para Aguiar (1), são as melhores lavouras da região.

Lindley (4) (em 1802-3) discorre ainda que este produto é essencial para a alimentação desde os prisioneiros da corte portuguesa e de moradores de rua, até mesmo soldados, pessoas de classes mais abastadas, como fazendeiros e militares de altas patentes; sendo, portanto, item essencial na mesa dos baianos oitocentistas. Sobre os hábitos de comer em Porto Seguro ele relatou: "Primeiro tomam entre os dedos um pouco de carne (que é sempre tão bem passada que se separa facilmente) e, depois, legumes e farinha" (Lindley, 1969, p. 63).

Devido ao seu potencial gastronômico (enraizados cultural e socialmente), a farinha se mostra como gênero financeiro importante na Bahia oitocentista, abarrotando as feiras das cidades e interiores na Província e servindo como importante meio de pagamento, em especial a soldados, marinheiros, navegantes, feirantes etc: "Os fortes principais, que podem ser considerados em serviço ativo, pagam somente três xelins e quatorze dinheiros por dia a seus comandantes, acrescidos de uma pequena quota de farinha" (Lindley, 1969, p.91). Para Aguiar (1), porém, o que impedia esse gênero de ter maior repercussão econômica, era a dificuldade de transporte. Para o autor "a Bahia para exceder-Ihes só precisa de fáceis meios de transporte [...], pois planta-se limitadamente e são vendidos por preços relativos a $2 \$ 000$ por carga de farinha" (Aguiar, 1979, p. 307).

\section{A Cultura da Cana-de-Açúcar}

Thomas Lindley (4) e Johann Rugendas ${ }^{(5)}$, destacam a cana-de-açúcar (ou comumente chamada de açúcar) como potencial monocultura da região desde o início do século. Rugendas (5) ao fazer um relato visual das paisagens da Bahia oitocentista, descreve que na passagem entre Cachoeira de Santo Amaro: "Erguemse colinas de cimo achatado, cobertas de florestas e plantações de açúcar e café. Já à beira dos rios e do mar somente se encontram plantações de açúcar" (Rugendas, 1954, p. 74). 
Lindley ${ }^{4}$ também discorre sobre a influência da cana-de-açúcar na paisagem de Porto Seguro: "Ao fim de duas horas de vigorosa cavalgada, a paisagem abriu-se de nôvo, e passamos por diversas lavouras de cana-de-açúcar, em terras parcialmente arroteadas" (p. 40). Para Aguiar (1), a cultura do açúcar no final do século é de fato tão necessária, que "a plantação é permanente" (p. 23), sendo plantada toda vez que necessário.

Os principais produtos da cana-de-açúcar observados, sem dúvidas, são o açúcar, a raspadura e a aguardente. Essa produção era realizada nos engenhos, que é apresentado por Lindley (4):

A palavra engenho é o termo português que caracteriza as terras que possuam uma fábrica de açúcar. O que vemos aqui é muito simples, consistindo em três cilindros de pesada madeira, de dois pés de diâmetro por três de comprido, os quais giram horizontalmente numa armação. A parte superior do cilindro central articula-se com uma viga que sobe pela armação, sendo nela fixadas peças transversais suficientemente baixas para nelas serem atrelados dois cavalos, que fazem mover o conjunto. Os cilindros laterais trabalham por meio de uma engrenagem que os liga ao central. Debaixo dessa máquina existe um cocho comprido, inclinado, pronto a receber o caldo da cana comprimida pelos cilindros. Esse caldo é transportado para um caldeirão raso, de seis pés de diâmetro, onde são escumadas todas as impurezas. Depois de esfriar noutra vasilha, adiciona-se-lhe um álcali de cinzas de madeira, deixa-se que a mistura assente por alguns dias, e decanta-se o líquido puro, levado, então a uma caldeira para evaporar-se até formar o açúcar" (p. 41). "O sedimento é destilado, produzindo forte aguardente (Lindley, 1969, p. 42).

Apesar da distância de quase um século entre a viagem e os relatos de Lindley ${ }^{(4)}$ (em 1802) e de Aguiar ${ }^{(1)}$ (em 1880), a tecnologia para produção do açúcar não adquiriu grandes transformações ao longo dos oitocentos: "existem nesses terrenos umas 60 engenhocas de madeira, movidas por bois ou à mão, e que, com tão grosseiros maquinismos, gastam um dia para moer um carro de cana, da qual deixam perder seguramente a quarta parte do caldo, apesar de ser passada por vezes na moenda" (Aguiar, 1979, p. 24). Apesar disso, o mesmo relato destaca que essa produção é alta e de bom gosto: "esses engenhos fabricam anualmente 50 a 60 arrobas, mais ou menos, de açúcar de excelente qualidade, além da rapadura e mel para aguardente" (p. 24).

A lavoura da cana era próspera e farta em todas as cidades na qual Aguiar (1) passou, apesar "da decadência pela falta de braços" (p. 307) - resultado da abolição 
da escravatura na metade daquele século. A fartura do açúcar e sua influência na economia do final do século é mostrada na maioria das cidades visitadas pelo mesmo viajante, em especial nas regiões ribeirinhas ao Rio São Francisco, no Imperial Vila da Vitória, Amargosa, Maragogipe e na capital. Sobre Santo Amaro, que também ganha destaque por sua produção e comércio de cana e seus derivados, assim como em Rugendas (5) (1954, p. 75), Aguiar (1) relata ser esta localidade de "qualidade especial para a cultura da cana, chama a atenção para os inúmeros engenhos, sendo a maior parte deles movidos a força hidráulica" (1979, p.104) onde o cheiro de mel fermentado ou dos resíduos de cachaça são sentidos ao longe.

Os autores trazem ainda relatos sobre o tão famoso efeito alucinógeno da aguardente. Lindley ${ }^{(4)}$ discorre que "Deixou-se ficar toda a tarde, conversando com curiosa reserva até que o frequente recurso [...] à aguardente da mesa removeram seu constrangimento" (p. 95); ou mesmo, "[...] tomar um copo de aguardente diluída, para levantar o ânimo..." (1969, p. 120). Tal produto era muito frequente também nas ordens de pagamento de marinheiros e barqueiros que atravessavam a Bahia de Todos os Santos para chegar à llha de Itaparica. O uso da farinha e da raspadura para o barqueiro, como relata Aguiar ${ }^{1}$, servia para se preparar a Jacuba, uma espécie de regalo para os barqueiros, indispensável para se fazer uma viagem tranquila. Os alambiques mais importantes eram os das cidades de Buracão do Campo Lago, Santana do Catu, Santo Amaro, Morro do Chapéu, Minas do Rio de Contas e Amargosa ${ }^{(1)}$.

\section{Frutas, verduras e outras espécies}

O solo fértil do Brasil, como já citado, atraia visitantes às diversas províncias do Brasil colonial. Na obra de Rugendas (5), o pintor destaca a diversidade da flora e fauna em seus desenhos e em seus relatos. Ao falar sobre a costa da Bahia, o viajante discorre: "Em geral essa costa é uma das mais cultivadas e férteis do Brasil" (Rugendas, 1954, p. 74). Os mercados de Salvador eram abastecidos, em sua maior quantidade, por produtos provenientes dos interiores e da llha de Itaparica, próxima ao porto: 


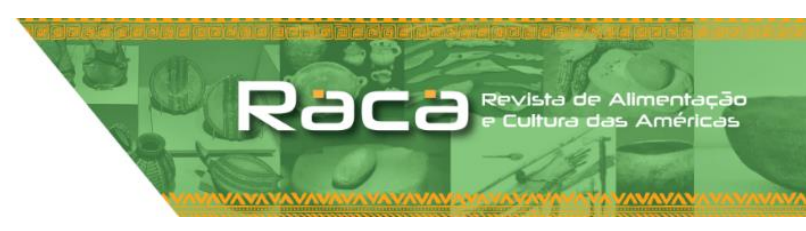

DOI 10.35953/raca.v1i1.31

"A Ilha de Itaparica, em frente da Baía [...] é muito fértil e abastece o mercado da cidade de toda espécie de legumes e frutas. Todas as manhãs parte para a Baía uma pequena frota carregada desses mantimentos" (Rugendas, 1954, p. 74).

Sobre essa variedade de produtos, Lindley ${ }^{(4)}$ descreve em sua passagem ao mercado do Porto:

Caminhei até o mercado de legumes e frutas, na praia, onde aportam lanchas, diariamente, provindas de inúmeras angras e rios da baía e da costa vizinha, para aí depositar seus carregamentos de legumes. Essa copiosa amostra de produtos tropicais é um espetáculo vistoso e agradável. A praça do mercado estava repleta de cocos, melancias, melões, abóboras, pesados cachos de bananas-de-sãotomé, deliciosas laranjas doces de procedência europeia e laranjas da China, que são menores, lado a lado com a melhor, a espécie nativa, ácida, levada deste continente para Sevilha. O ananás, trazido do mesmo modo, é pouco apreciado aqui, sendo certamente inferior ao nosso, embora este seja obtido artificialmente. Além desses produtos, há quantidades imensas de outras frutas, tais como jacas, mamões, jenipapos, goiabas, mangas, tamarindos, gengibres, mangabas, etc. São abundantes os artigos culinários: o repolho, a mandioca, o feijão, o pepino e a alface, tudo isso realçado pelo perfume dos buquês vendidos por mulheres mestiças de tapuias, e consistindo em jasmins, cravos e rosas, todos de especial fragrância. Andei de um lado para outro a examinar aquele espetáculo variado, enquanto perdurou a fresca da manhã, até que os raios do sol, tornando-se desagradavelmente quentes, começaram a provocar exalações pouco amenas dos legumes em decomposição, provindos de feiras anteriores, e que nunca são removidos (Lindley, 1969, p. 90).

Ainda sobre os produtos observados por Lindley ${ }^{(4)}$ destacam-se em sua obra: $\mathrm{Na}$ cidade de Salvador: pimentas e jabuticabas no bairro de Matatu; limas, laranjas e melões, considerados "dieta barata" (p. 114); uvas, que apesar do calor excessivo e cultivo de frutos de qualidade inferior (p. 134), podem ser encontradas em alguns poucos pomares de Salvador; bananas e cocos, que "de tal abundância, não tem menor valor" (p. 150). Em Porto Seguro, nos informa que: "São infinitos os produtos de origem vegetal, mas os habitantes mal possuem quaisquer conhecimentos a respeito, salvo quanto àqueles imediatamente relacionados ao seu benefício" (Lindley, 1969, p. 154). Essa informação nos leva a supor a falta de referencial gastronômico na Bahia do início dos 1800.

Aguiar (1), na década de oitenta, chama atenção dos produtos vegetais da Província, como forma de mercar o valor desse solo: 
Enquanto não fornece o solo a recompensa do trabalho, a sábia Província se incumbirá da alimentação do colono, fornecendo-lhe, entre muitas frutas silvestres que profusamente espelhou pelos tabuleiros - o araçá, o umbu, o cajuí, a mangaba, o saborosíssimo piqui, de cuja polpa também se extrai uma gordura para o tempero da comida, e o buriti, coco, do qual tira-se uma massa amarela, gostosa, substancial e de efeitos afrodisíacos, a qual denominam saeta que geralmente toma-se diluída no leite ou feita doce. Estas frutas se encontram em todos os demais termos do S. Francisco, porém com menor prodigalidade por causa da devastação do povo, especialmente de gente pobre para quem servem de alimento, além de azeite, igual ao de cheiro, que dão (Aguiar, 1979, p. 48-9).

Para Aguiar (1), os vegetais são muito variados, nas diversas cidades da Bahia oitocentista. Ao exemplo de: "melão, mangaba, o buriti, a abóbora [...] e a melancia de um tamanho enorme" em Xique-Xique (p. 58); Cajá e umbu, que em Geremoabo "não desampara os pobres em épocas de severa estação" (p. 77); em Inhambupe, o cambucá, delicioso fruto (p. 89); Coqueiros em Abrantes (p. 102); ensaios de uva e trigo em Vila Nova da Rainha (p. 120); os óleos vegetais, especialmente o azeite de Palmeira, em Lençóis, que segundo o viajante "bem substitui o azeite doce no tempero" (p. 139) e o azeite de mamona em Curralinho (p.228); abundam a mangaba, o cajuí, o piqui e a banana em Caetité (p. 181-3); As principais frutas silvestres que o autor (1) cita em Imperial Vila da Vitória (atualmente Vitória da Conquista) são: "Jaboticaba de três espécies, grapiá, mandapuçá, araticum, Guabiraba, cambuí, murici, cajá, umbu, olho de boi, sapucaia, araçá, goiaba, maracujá, etc." (p. 214). Em Morro do chapéu, Itiúba, Serra do Rio de Contas, Aguiar relata que "se obterá, como na Europa, o trigo, a uva, o pêssego, a pera, os morangos, a maçã etc., etc" (p. 309), talvez por conta da adaptação do clima.

Aguiar destaca ainda que possui a Bahia privilégio natural sobre o cacau, em particular nas cidades de Ilhéus, Canavieiras, Vila Nova da Rainha e Morro do Chapéu; e a cultura do café, em Camisão, Morro do Chapéu, Minas do Rio de Contas, Imperial Vila da Vitória e Amargosa - frutos importantes para a alimentação e economia de diversas cidades da Bahia. Sobre a Bahia de Todos os Santos, discorre:

Em nada invejamos a velha Europa, que dela possuímos aclimados todos os espécimes, enquanto por lá nem nas estufas ainda conseguem colher umas das nossas clássicas bananas, [...], mangas, laranjas, jacas, pinhas etc., etc., que constituem por cá o gozo dos selvagens brasileiros. [...] todas as costas do litoral, onde 
abundam o peixe, as frutas em barateza relativa a profusão; se, porém, precisardes de clima seco, salubre e alimentação nutritiva, é nosso obsequioso sertão o melhor refúgio (Aguiar, 1979, p. 309)

\section{Das carnes, peixes e mariscos}

Devido a vasta fauna presente no Brasil, a variedade de animais comestíveis na alimentação da Bahia oitocentista, citada pelos viajantes é grande. Isso se tornou outro ponto importante observado nas leituras. A cultura de se comer peixes, tão presente nas populações indígenas, aliado a proximidade da costa, torna a pesca (em especial de baleias) uma atividade frequente, e, devido ao seu potencial marítimo, populações da Província sobreviveram à base dessa atividade, em especial na llha de Itaparica ${ }^{(5)}$. O destaque da pesca de baleias pode ser explicada pelo fato de que além desta ser uma carne barata à época, ela produzia outros derivados importantes para a economia, como o óleo, que apesar de não ser utilizado para alimentação era produto importantíssimo de exportação (Lindley, 1969, p.110).

O consumo de peixes e frutos do mar está presente em toda obra de Lindley. O navegante inglês, afirma ser o peixe, seco ou fresco, principal carne das dietas baianas, mas que, apesar da grande oferta desse produto, a pesca é feita apenas por pescadores e companhias, que encarecem o valor.

\footnotetext{
Esta baía produz grande cópia das espécies escamosas, e numa variedade imensa. Nunca vi peixes de cores tão lindas: há um de pequeno porte, amarelo e preto, chamado soldado; outro grande e purpúreo, da espécie da carpa; outro ainda, chato, branco e transparente; e diversos que eu considero indescritíveis ou, se conhecidos, mostram-se tão singulares que seria preciso uma obra sobre ictiologia para ajudar minha memória (Lindley, 1969, p.116).
}

Aguiar ${ }^{(1)}$, em 1880, também compartilha sobre a importância do peixe para as populações baianas. Para as regiões próximas ao Rio São Francisco, o autor mostra o consumo do dourado, que, "além de muito gordo e saboroso, o dourado do Corrente é muito apreciado por causa da língua, que é de um gosto delicado" ( $p$. 29), além do "peixe de salmoura ou seco, especialmente o saboroso surubi 
destinado, sem dúvida, a substituir o bacalhau" (p. 73). Em Alagoinhas (p. 93) e Ilhéus (p. 264), "os peixes e marisco, em profusão, gozam de preços insignificantes".

Em Porto Seguro a "pesca da saborosa garoupa, em que se ocupa muita gente [...] sendo as garoupas pescadas, logo abertas e postas em salmoura, depois do que são empilhadas nas lanchas garoupeiras que as exportam para todos os portos da província" (p. 282). De maneira geral, na Bahia oitocentista, "os rios são abundantes em peixes; traíras, piau, crumatá, piabanha, mandi, espécie e de surubim, acará, pitus etc." (Aguiar, 1979, p. 214).

Os moluscos existem em abundância: ostras, mexilhões, lambretas etc., como também as tartarugas, que não são apreciadas, sendo mortas unicamente pelas suas carapaças. Os empregados escravos são incumbidos a apanhá-las nas praias arenosas e "até mesmo estes se recusam a comê-las, apesar de constituírem alimento tão raro entre nós e de preço tão elevado" (Lindley, 1969, p. 116). Na quaresma, o consumo desses produtos aumenta, devido à significante cultura religiosa, o que encarece esses produtos, chamam a atenção Aguiar e Thomas Lindley.

Em contrapartida, sobre o consumo de carnes frescas, os autores revelam ser escasso à época, devido à baixa ocupação da criação de animais para esse fim:

É curioso como tanto no interior como na capital, não se dá atenção
à carne. A carne de carneiro, cordeiro e vitela é praticamente
desconhecida, não se encontrando nunca no mercado. A carne de
vaca, nos dias em que existe, apresenta o mesmo e invariável
aspecto: é extremamente magra, mole e sem gosto; e as rases são
abatidas de modo tão sórdido, que a simples inspeção da carne
condenaria o seu uso, se a necessidade e o hábito não atenuassem
essa desagradável inconveniência [...]. Há carne de vaca, sendo
abatida somente uma rês, aos domingos; os melhores pedaços são
reservados para o governador e as autoridades da cidade, sendo os
restantes distribuídos entre o povo [...]. Seriam abundantes os porcos
e os carneiros, se fosse incentivada sua criação, pois as matas
proporcionam alimento inesgotável para esses animais. Mas os
habitantes são de tal maneira atoleimados, que dificilmente se vê um
porco, e nunca se encontra um bode ou carneiro (Lindley, 1969, p.
150).

Observa-se uma inversão desse costume no fim do século e nos interiores, pois Aguiar (1) cita com demasia a criação de gados, carneiros, cabras etc., sendo vendidas carnes frescas e secas nas feiras. Nas regiões mais próximas ao São Francisco, o consumo de carnes frescas é baixo: "Esse gado goza ali de um preço 
muito baixo (20\$000 mais ou menos por cabeça) em atenção à falta de consumo" (Aguiar, 1979, p. 22). Nos interiores de grandes secas, como em Geremoabo, Riachão do Jacuípe e Bom Jesus dos Meiras, a criação de gado era dificultada pela falta de forragens, fazendo com que as populações preferissem a criação de carneiros, cabras e bodes, animais mais resistentes à seca. Já nos lugares com mais verde e chuvas frequentes, como Feira de Santana, Monte Alegre, Imperial Vila da Vitória, Amargosa e Salvador, as feiras apresentavam grande oferta e procura de carne verde no final do século XIX, relata Aguiar.

Thomas Lindley chama a atenção para a baixa procura por carnes de criação. Isso talvez esteja mesmo relacionada a dificuldade de compra e criação do gado. Segundo o autor, o consumo de caças é alto, tanto na capital quanto nos interiores, afirmação comprovada pelos relatos dos viajantes no fim do século (1) (3). O hábito também pode ser explicado pela presença indígena que desde cedo utilizou a caça para o sustento do seu grupo.

Durante uma longa excursão, dei com os olhos num índio velho, em meio da mata [...]. Estava ele à espera de tatus, que raramente aparecem antes do anoitecer. São animais da espécie suína, aqui considerados belo manjar, embora eu julgue sua carne bem insípida, algo assim entre leitão e coelho. Essa caça brasileira é geralmente assada no casco (Lindley, 1969, p. 106).

A caça miúda é abundante em Bom Jesus da Lapa, como informa Aguiar (1), em especial o mocó em quantidade espantosa (p. 40). Para os lados do Brejão, em Morro do Chapéu, "muito abunda a caça, especialmente o tatu, mocó, caititu, gato do mato, porcos e até onça - suçuarana, verdadeira e Tigre” (p. 127). Em Ilhéus, macacos destacam-se, como excelente caça, "os da raça miriti, cinzentos, feíssimos de cara, barrigudos e grandes como um menino de 8 anos. Os caçadores os trazem das matas moqueados e inteiros; parecendo então um corpo de um menino [...], mas saborosíssimos" (p. 265). Em Salvador, "a produção da caça assemelha-se com a das províncias remotas. O veado e a anta, por serem os maiores, são muito comuns no sertão; o tatu, o teiú e a gorda e saborosa paca no litoral, e mesmo nos subúrbios da capital" (p. 308). 


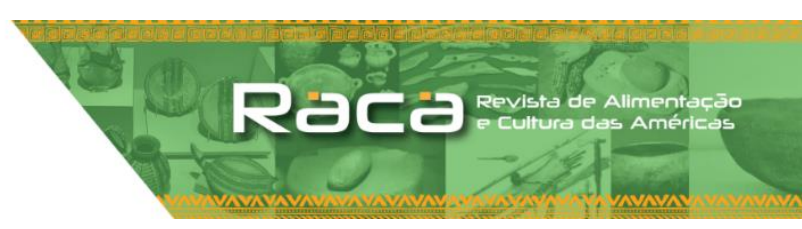

DOI 10.35953/raca.v1i1.31

\title{
Os hábitos alimentares e a comensalidade
}

\begin{abstract}
Os diferentes alimentos e os variados modos de comer, preparar os alimentos, de sentar-se à mesa, os utensílios utilizados... não passaram por desapercebidos pelos viajantes que transitaram na Bahia no século XIX. Das obras analisadas, o único trabalho que não traz explicitamente notícias sobre os hábitos alimentares na parte em que menciona a Bahia é o diário de Rugendas. Lindley (4), ao contrário, relata em todas suas passagens pelas cidades e vilas da Bahia hábitos alimentares, que podem demonstrar vários aspectos da comensalidade da época.

Em sua passagem por Porto Seguro relata:

A recepção foi acolhedora, os alimentos bem cozidos (para o país) e toleravelmente asseados. Jantamos no chão, sendo estendidas umas esteiras e, sobre elas, uma toalha limpa. A louça era suficiente (o que é raro aqui), como também as colheres, de prata, facas e garfos, com cabo do mesmo metal (Lindley, 1969, p. 42).
\end{abstract}

Em Salvador, o navegante também demonstra alguns dos hábitos convergentes as da população de Porto Seguro, destacando a disparidade da classe econômica entre as cidades:

Os pratos eram simples, porém muito superiores aos de Porto Seguro. Os convidados eram bem mais finos, embora eles tivessem o horrível costume do país, qual seja, o de comer com as mãos, em vez de usar facas e garfos, posto que não houvesse falta desses utensílios. Primeiro tomam entre os dedos um pouco de carne (que é sempre tão bem passada que se separa facilmente) e, depois, legumes e farinha. Mergulham isto no molho ou na sopa, que têm em abundância nos seus pratos, esmagam o conjunto na palma da mão, fazendo um bolo mais ou menos do tamanho de um pequeno sabonete, o qual, assim pronto, levam imediatamente à boca, preparando outro enquanto comem. Por mais grosseiro e repugnante que possa parecer este quadro, não lhe estou carregando as tintas. Ambos os sexos adotam por igual a mesma prática, que predomina em quase todas as classes. E até mesmo perante estranhos, se acaso tomam faca e garfo, cansam-se logo de um estilo tão pouco usual, lento e enfadonho; abandonam involuntariamente o talher e recaem no hábito antigo, com redobrada avidez. É verdade que, a exemplo do oriente, trazem-Ihes água antes e depois das refeições; mas isto não desculpa, de modo algum, esse costume bárbaro e pouco asseado (Lindley, 1969, p. 63).

Lindley chama a atenção para o hábito de comer alimentos mais cozidos, macios e informa também sobre o costume de comer com as mãos, considerado por 
ele como "horrível hábito", "grosseiro", "repugnante", "bárbaro" e "pouco asseado". O comer com as mãos, hábito comum entre os mais abastados na Europa e, também entre indígenas e africanos, perdurou no Brasil durante muito tempo. Os chamados talheres, garfo e faca, importados e geralmente de prata, além de serem reservados a ocasiões especiais, eram também utilizados para exibição de prestígio, em certas ocasiões e em algumas classes sociais.

O comer com os dedos, molhando carnes e verduras no caldo engrossado com farinha era comum entre os baianos. Ora, a farinha de mandioca desde cedo foi utilizada para engrossar a comida de caldo ou dar liga na comida - como até hoje geralmente se fala -, hábito confirmado por Lindley e por Habsburgo (3). Aguiar (1), no fim do século, mostra que, em Geremoabo e populações vizinhas, na falta de farinha, quando esta sobe a um preço exorbitante, "come a população pobre um tal de bró, que não é mais do que um amargo pó de serra extraído, a pancadas de machado, do tronco do nicuri; depois lavam e torram. O uso frequente desta substância ocasiona inflamações de toda espécie e até suspendem a regra às mulheres, que ficam anêmicas e inchadas" (Aguiar, 1979, p. 76). Fato é, como ainda hoje, em alguns locais, o sabor de algumas comidas está associada a esta forma de comer utilizando as mãos e acrescentando a farinha ao caldo para engrossar ou fazer alguns bolos chamados em alguns lugares de "capitão".

Sobre as formas de se alimentar dos baianos, Lindley discursa:

[...] são todos extremamente frugais na alimentação, embora isto não signifique falta de apetite ou hábitos de temperança, mas avareza, porque não há quem coma com melhor disposição nem beba mais do que eles quando participam de mesa farta, desde que não seja à própria custa. Toda a gente, aqui, dificilmente se alimenta a horas certas, mas servem-se quando assim o pedem os caprichos do estômago (Lindley, 1969, p. 49).

A "mesa farta" é outra observação comum nos relatos dos viajantes. Lindley (4) afirmou que esse costume está presente em todos os momentos da vida dos baianos, em especial, em festas como o Natal, que "é celebrado como um grande feriado" (p. 98) e na Páscoa, com "a perspectiva de comer carne outra vez, que é servida em grande quantidade, neste dia" (p. 124). Sobre a quaresma, Lindley (4) indica que, assim como na Europa, a alimentação é regrada pela "severidade 
costumeira" (4) (p. 112). Lindley ainda revela o costume de "banquetes" pelas grandes classes: "O termo não foi impropriamente empregado porque já antes do fim a festa foi celebrada com uma orgia de verdadeira bacanal' (Lindley, 1969, p. 133).

A fartura das mesas também é observada nos relatos de Aguiar, quando o viajante mostra que nos mais diversos interiores e cidades do final do século XIX, as feiras eram abarrotadas de gêneros, representando simbolicamente o fascínio dos baianos pela fartura de comida e de Habsburgo, ao notar as cestas entupidas de frutas, artefato das mesas das grandes casas na Capital.

Outro destaque para a fartura de comida nas mesas dos baianos está nas refeições secundárias, como nos lanches. Lindley ${ }^{(4)}$ conta que a colação usual dos brasileiros finos era frutas, doces em compota, pão, vinho e licor (Lindley, 1969, p. 106) e que piqueniques eram frequentes em todas as classes: "das mais abastadas aos pobres com uma grande diversidade de frutas, nativas dessa região" (Lindley, 1969, p. 180).

Aguiar, da mesma maneira, discorre sobre os lanches e destaca, em Mata de São João, os bolinhos de goma, "que na capital não sabem imitar, assemelhandose, no sabor, a uns da mesma massa, que, fritos no toucinho, dão no Rio São Francisco, o nome de petas; e tomados com café, servem de regalo aos hóspedes para esperarem pelos lautos almoços" (Aguiar, 1979, p. 101).

Outro hábito com frequência observado é o consumo de café, que Lindley (4) descreve ser "um líquido nojento que se torna ainda mais repelente à vista pelo fato de ser servido em copos" (p. 175):

São inúmeros os cafés. Existem em todas as ruas, desde que se possa conferir a dignidade desse nome a uma casa suja, em cuja parte da frente se alinham algumas mesas e bancos, havendo, nos fundos, uma espécie de bar [...]. Todas as manhãs, esses lugares ficam apinhados de gente de todas as classes, pessoas respeitáveis e o vulgo, que conseguem fazer uma primeira refeição por quatro vinténs: consiste num copo de café e um pãozinho com manteiga irlandesa, rançosa, refugo do mercado de Lisboa (Lindley, 1969, p. 175).

Já Aguiar, descreve que "o sistema de vida é o mesmo em qualquer parte das Lavras, onde se encontra sempre os mesmos gêneros, iguais hábitos, a mesma alimentação e o legendário costume de beber-se durante o dia um saboroso café, que a etiqueta local obriga a oferecer-se aos hóspedes a qualquer hora recebidos" 
(p. 146). A divergência dos relatos entre Lindley (4) e Aguiar (1), além de se configurarem na esfera do gosto pessoal, podem representar também a disparidade na cultura do café, que era baixa no início do século (com Lindley) e vai ganhando destaque com o passar dos anos, forjando o hábito do seu consumo pelas populações na Bahia. Assim, pode-se identificar que o costume de se beber café durante todo o dia, como ocorre em diversas regiões até hoje, está presente há séculos.

Além dos hábitos mencionados, no início do século o preparo de alimentos como pães, massas, doces etc., não era valorizado pelos povos:

A arte culinária está inteiramente fora de cogitações, pois a alimentação usual não a exige ou admite. E são tão completamente ignorantes desses complementos de nosso bem-estar que não consegui, percorrendo toda a cidade, fosse transformado em pão um pouco de farinha que possuía. [...] A província [comarca] tem fartura das mais deliciosas frutas para conservas; mas o seu preparo é totalmente desprezado pelas mulheres. [...] São infinitos os produtos de origem vegetal, mas os habitantes mal possuem quaisquer conhecimentos a respeito, salvo quanto àqueles imediatamente relacionados ao seu benefício (Lindley, 1969, p.154).

Esses hábitos mudam com o decorrer do século, ao observar, no final do século, quando Aguiar (1) aponta a produção de "cuscus com raiz de mandacaru" (p. 145); ou a de "uma espécie de tijolo não maus de comer", feitos de uma massa ralada de raiz de mangabeira ou umbuzeiro e misturada com raspadura (p. 77) e até de doces, como destaca em Jacobina.

Constitui a indústria local o fabrico da goiabada, vulgarmente conhecida por doce de araçá de Jacobina [...]. Nas épocas dessa fruta fazem as doceiras enormes provisões, de onde tiram 0 suprimento para o ano inteiro; entretanto como o vinagre do vinho, difere esse doce de carregação, feito de fruta fermentada, do doce que ali fazem para encomendas, de uma qualidade sem rival em parte alguma. Da mesma maneira trabalham o marmelo, umbu e limão (Aguiar, 1979, p. 125).

É digno de nota observar também que a ausência do relato de algumas preparações como doces, pães e algumas receitas que fizeram fama na nossa culinária talvez não tenham sido registradas por estes, haja vista também o local em que elas eram preparadas: a cozinha, que a sua maioria, ainda no século XIX continuava sendo uma parte anexa às dependências da casa. Não era comum receber visitas na cozinha, lugar onde escravos e senhoras disputavam espaço e 
DOI 10.35953/raca.v1i1.31

nas poucas vezes que alguns destes visitantes tiveram acesso, as descreveu observando à chamada limpeza e ordem.

\section{Considerações finais}

Através deste levantamento foi possível identificar alguns hábitos e costumes alimentares dos povos da Bahia no decorrer do século XIX. Neste mapeamento, através das obras de Lindley ${ }^{(4)}$ e Rugendas ${ }^{(5)}$ (datadas do início do século) e Aguiar (1) e Habsburgo (3) (datadas do final do século), conseguimos fazer cortes historiográficos da alimentação na Bahia oitocentista. As obras de Lindley e Rugendas tiveram maior aproximação com os resultados dessa pesquisa e por isso foram as mais utilizadas.

Em "Província da Bahia", Aguiar (1) (apesar de pouco relatar a comensalidade dos baianos em 1888), mostra com veemência a importância da lavoura e abate de animais na alimentação, economia e auto sustento das terras da Província, demonstrando a importância das vilas fronteiras ao Rio São Francisco, Feira de Santana, Santo Amaro, Cachoeira, Valença e Imperial Vila da Vitória (atualmente Vitória da Conquista).

Lindley (4) transmite com clareza e objetividade os hábitos alimentares e gêneros alimentícios mais comumente consumidos e mercados na Bahia, em 18023. Mesmo que de forma sucinta, o navegante mostra os hábitos alimentares dos povos em festas sacras, como as mesas fartas na Páscoa e Natal e o costumeiro e severo jejum penitencial na quaresma, pelos devotos do cristianismo, mostrando assim que a alimentação na Bahia se configura atrelada aos hábitos religiosos. O navegador também relata, nos primeiros anos dos oitocentos, o costume dos banquetes promovidos por pessoas ricas e influentes na Província, que se tornavam um verdadeiro bacanal, com direito a muita bebedeira e orgia. Esses relatos nos fazem refletir a importância da comida no contexto das celebrações, reverberandose como um convite à satisfação dos prazeres.

Habsburgo (3), em "Bahia 1860: Esboço de uma vagem", apesar de não se ater às questões da alimentação, se vale em sua escrita sobre a botânica encontrada na cidade de Salvador, e assim mostrou, em algumas passagens o 
mundo vegetal, em especial a cana e coco. Com olhar estrangeiro, destacou a importância das mulheres negras na venda de frutas na cidade, em especial bananas, cocos, mangas, cajus e jacas.

Apesar de Rugendas ${ }^{(5)}$ apresentar muitos dados relevantes sobre a cultura alimentar dos povos brasileiros, fazendo uma observação muito específica das culturas (separando cidades, interiores, negros, índios e 'brancos'), fazendo-o em escritas e pinturas de grande valor, estes resultados são apresentados de forma muito geral, não relatando sobre os costumes destes povos na Bahia (a não ser por duas partes específicas em que discorre sobre os usos e costumes na Bahia e sobre a vida do estrangeiro na Bahia, partes estas aproveitadas para escrita deste produto final).

Após apresentar estes resultados consideramos importante destacar a interpretação historiográfica que realizamos. No início do século é possível identificar a persistência de alimentos como o protagonismo da farinha (mandioca) e a importância do açúcar (cana-de-açúcar), aguardente, carne-sêca, peixe salgado (inclusive baleia) e diversas frutas e legumes (dentre os quais aparece na leitura em diversas ocasiões a laranja e o melão). A farinha é o principal gênero para a economia da Bahia (sendo produto tanto de exportação, como de pagamento de empregados, passando também como principal alimento para os pobres - presos, indigentes e doentes). As formas como são processadas a farinha e o açúcar e outros derivados, através de seus gêneros primários, mostravam mecanismos ainda muito rudimentares, como as máquinas de moer mandioca feitas de pedra e os engenhos que necessitavam dos braços dos escravos, relatos de Thomas Lindley.

Os livros datados no fim do século (1) (3), mostraram o protagonismo da cana de açúcar e seus derivados (em especial açúcar e raspadura) na comensalidade dos baianos e para a economia das vilas e regiões. A crescente lavoura e consumo de café, pouco observado nas obras do início do século, e criação de gado destacamse como gêneros importantes na alimentação e economia da Bahia no final do século XIX, assim como o experimento para lavoura de trigo, uva e outros gêneros, e o consumo e comércio de frutas silvestres e vegetais. O protagonismo da farinha, apesar de muito presente, perde espaço para o açúcar e raspadura. 
DOI 10.35953/raca.v1i1.31

Nos visitantes analisados a substituição de produtos e alguns hábitos dos portugueses como a farinha de trigo pela farinha de mandioca; o azeite de oliva, já aqui chamado de "azeite doce" pelo azeite de dendê; o surubim pelo bacalhau, seria o resultado, ora da falta de adaptação de algumas culturas, como o trigo, e da dificuldade de se encontrar. Esta ideia está presente entre alguns autores até hoje. Todavia, é consideável chamarmos a atenção que a maior presença ou ausência de certos hábitos alimentares está também relacionada a aspectos culturais, onde as dietas da África Ocidental e dos ameríndios forneceram matrizes sensíveis que ajudaram a constituir o que hoje chamamos de cozinhas brasileiras e em especial cozinhas baianas.

A análise dos relatos sobre a alimentação na Bahia no século XIX nos possibilitou identificar alimentos, hábitos alimentares e a comensalidade que está enraizada na história dos de comer dos baianos, interagindo com os aspectos geográficos, socioculturais e econômicos ali representados. Os resultados aqui obtidos conseguem nos dar um panorama mais amplo sobre os de comer dos baianos oitocentista, pois com eles, conseguimos entender como os alimentos e hábitos se misturam na formação do patrimônio alimentar desse povo. Por fim, os de comer da população nos oitocentos cruza em diversos momentos com os hábitos alimentares contemporâneos, mostrando a formação social e histórica através da comida, que, sem pertencer a um tempo definido é capaz de revelar a identidade dessa população.

\section{REFERÊNCIAS}

(1). Aguiar DM. Província da Bahia. 2. ed. Rio de Janeiro: Ed. Cátedra, Instituto Nacional do Livro; 1979.

(2). Augel MP. Visitantes estrangeiros na Bahia oitocentista. São Paulo: Cultrix, Instituto Nacional do Livro; 1980.

(3). De Habsburgo M. Bahia 1860: Esboços de viagem. Rio de Janeiro: Tempo Brasileiro, Fundação Cultural do Estado da Bahia; 1982.

(4) Lindley T. Narrativas de uma viagem ao Brasil. São Paulo: Companhia Editora Nacional; 1969. 
DOI 10.35953/raca.v1i1.31

(5). Rugendas JM. Viagem Pitoresca através do Brasil. São Paulo: Martins Fontes; 1954.

(6). Vianna, H. A Cozinha Baiana: seu Folclore e suas Receitas. 2. Ed. São Paulo: GRD; 1987. 